for industry, indicated that a sub-committee has already completed its report on the scope and plan of the proposed new Central Scientific Reference Library, although the report has not yet been made public. Mr. Francis emphasized, however, that no one library could provide all the service now required, and that the elaboration of scientific library services in Great Britain demands the greatest possible spreading of responsibility. The function of the National Library is to cover the greater part of the field itself and to co-ordinate the activities of the other libraries, seeking to ensure that all fields of information are properly covered.

Beyond the announcement that the proposed Science Centre is to be on a site on the south bank of the Thames, there has been no official pronouncement since Sir Robert Robinson's reference to the scheme in his anniversary address to the Royal Society on November 30,1950 . The site for the National Library has also been chosen, and the Ministry of Works has requested the London County Council to designate for this purpose in its first development plan the area lying opposite the British Museum on the south side of Great Russell Street. It is proposed that eventually the library of the British Museum shall be separated from the museum departments and accommodated in its own building on this site, much as, some seventy years ago, the natural history collections were transferred to South Kensington. Both projects will require many years for completion, and even the detailed planning is scarcely in sight. Nevertheless, Mr. Francis rightly directed the attention of the Library Association to both the short-term and the long-term problems which such projects pose, and to the challenge they offer to constructive thinking as well as to cooperation. That challenge should be taken up by the scientific worker and technologist as well as the librarian, and indeed by all who appreciate the large part which libraries can play in the dissemination and assimilation of our scientific and technical knowledge. As Mr. Francis indicated, prime importance is attached to the whole matter by the Government ; but if the opportunities are to be utilized to the full and all obstacles to achievement overcome, the Government will require the sustained support over a period of years of informed opinion in scientific, technical and industrial circles.

\section{RESEARCH ON BRICK-MAKING}

\section{NEW RESEARCH LABORATORIES OF THE LONDON BRICK CO., LTD.}

$\mathrm{O}$

VER a large area of Great Britain the fletton brick has won its place as the cheapest common brick of the building industry, and an annual output of more than 2,000 million is nowadays achieved by the group of brickworks situated on the Oxford clay in the districts lying mainly around Bedford and Peterborough. In any manufacturing industry operating on this scale it is to be expected that there would be many problems calling for research, and a notable advance has recently been made by the largest fletton manufacturer, the London Brick Co., Ltd., which has recently opened new research laboratories at its Stewartby works near Bedford. The building, which was designed by Mr. C. C. Handisyde, provides efficient accommodation for the strong research team that has been built up since the War and, in addition, includes a display hall, library, and directors' conference and dining rooms. It is perhaps significant of the changes which are coming about in even the more traditional of our industries that accommodation for the Company's directors should be provided in close association with the research laboratories.

The laboratories are, naturally, built of brick. They are on an ample site and are designed in three wings on one floor on a flexible plan which will facilitate any future extensions that may be needed. Offices and small laboratories open off central corridors, and the lessons of modern school design have been utilized in that the larger laboratories obtain cross-ventilation and additional lighting over the corridors.

Other interesting features are the use of ceiling heating-panels in the laboratories to avoid the loss of valuable wall and floor space which other forms of heating would have required, and the imaginative use of bright, pleasant colours throughout the building in the decorations. Even the service pipes, which, owing to the nature of the site, could not be accommodated in under-floor ducts, are picked out in various colours in accordance with recommendations issued by the British Standards Institution.

Much of the research work is aimed at improving both the understanding and the operation of the manufacturing processes used in the Company's works, and studies are in hand on the conditioning and grinding of the clay, on the methods of pressing it into green bricks, and on the drying and firing processes involved. It is something of a surprise to find a well-equipped fuel technology laboratory devoted mainly to a study of the fuel content of the natural Oxford clay. Theoretically, the organic content of most of the clay used in the works is sufficient to produce all the heat needed for burning the clay. In fact, on account of the unavoidable inefficiencies of the burning process, some additional fuel has to be provided; but this is only a quarter of that needed for burning most other types of bricks. This is a matter of great economic importance in the fletton industry.

As an essential part of the research on plant and methods, a close statistical watch is kept on the qualities of the bricks emerging from the various works. By this means the effects of changes both in the manufacturing processes and in the nature of the raw clay can be accurately followed. Research of this kind is badly needed in a group of industries which are normally regarded as falling outside the field of chemical engineering, and it may well be that this pioneering work by the London Brick Co. will lead other industries to make similar efforts.

Work of a much more fundamental character is also being done. In association with a detailed geological survey of the Oxford clay deposits, a study has been commenced of the constitution of the clay. Differential thermal analysis is being used for the identification of clay minerals, and provision has been made for the utilization of X-ray techniques at a later stage. These are essentially long-term investigations and represent an imaginative and long-sighted view by the Company of its research activities.

In addition to the work concerned directly with brick manufacture, there is also some research in hand on processes designed to produce a light-weight aggregate for concrete by the bloating of clay, and other clay products of cellular structure. Attention is also given to the utilization of by-products. 